\title{
Cronkhite-Canada Syndrome: A Rare Cause of Chronic Diarrhea
}

\author{
Umair Iqbal ${ }^{\mathrm{a}, \mathrm{c}}$, Ahmad Chaudhary ${ }^{\mathrm{a}}$, Muhammad Arsalan Karim ${ }^{\mathrm{b}}$, \\ Hafsa Anwar ${ }^{\mathrm{b}}$, Nancy Merrell ${ }^{\mathrm{a}}$
}

\begin{abstract}
Cronkhite-Canada syndrome (CCS) is a rare non-hereditary disease characterized by chronic diarrhea, diffuse intestinal polyposis and onychodystrophy. We present here a case of a middle-aged female who presented with chronic intermittent bloody diarrhea associated alopecia and loss of finger and toe nails. Labs were remarkable for microcytic anemia and severe hypoalbuminemia. Endoscopy showed numerous polyps scattered throughout the colon. She was treated with nutritional support and corticosteroid with complete resolution of her symptoms and endoscopic findings. CCS is associated with high mortality and gastrointestinal malignancies. Clinicians should consider CCS in a patient with unexplained chronic diarrhea and ectodermal abnormalities.
\end{abstract}

Keywords: Cronkhite-Canada syndrome; Chronic diarrhea; Onychodystrophy; Intestinal polyposis

\section{Introduction}

Cronkhite-Canada syndrome (CCS) is a rare disease characterized by chronic diarrhea, weight loss, protein-losing enteropathy, malnutrition and ectodermal abnormalities [1]. It is associated with gastrointestinal (GI) malignancies and high mortality $[1,2]$. Early diagnosis is important as early application of nutritional therapy can prevent morality associated with this serious disease. We report here a case of CCS in a middleaged female with successful management.

\section{Case Report}

A 55-year-old Korean female with a history of hypothyroidism presented with complaints of chronic intermittent bloody diarrhea, nausea, abdominal pain and weight loss for 2 months.

Manuscript submitted March 06, 2017, accepted April 03, 2017

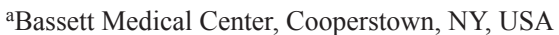

bDow University of Health and Sciences, Karachi, Pakistan

${ }^{\mathrm{c} C}$ Corresponding Author: Umair Iqbal, Bassett Medical Center, Cooperstown,

NY, USA. Email: umair.iqbal@bassett.org

doi: https://doi.org/10.14740/gr820w
Associated symptoms were alopecia and loss of finger and toenails. She also reported loss of taste sensation. Physical examination showed onychodystrophy and loss of finger and toenails. Physical exam also showed bilateral symmetric edema in lower extremities. Labs showed albumin $1.2 \mathrm{~g} / \mathrm{dL}$, INR 1.4 and hematocrit of 24.3 with normal liver and serum chemistries. Stool culture, ova and parasites were negative. EGD revealed extensive gastro-duodenitis with gastric biopsy showing edema and marked mucosal hyperplasia and small bowel biopsy showing inflammation and blunting of the villi. On colonoscopy, innumerous polyps were seen scattered throughout the colon (Figs. 1 and 2). It also showed $45 \mathrm{~cm}$ big polyp in a sigmoid colon (Fig. 3). Biopsy showed polyps to be inflammatory with adenomatous change. The clinical, endoscopic and histopathological findings favored the diagnosis of CCS. She was treated with total parenteral nutrition along with corticosteroids and had complete resolution of her cutaneous symptoms and colonoscopic findings. Corticosteroids were then gradually tapered down and azathioprine was added. She is now in remission for 5 years on azathioprine and budesonide.

\section{Discussion}

CCS is a rare non-inherited disorder with incidence of one in a million [3], first reported in 1955 by Leonard Cronkhite

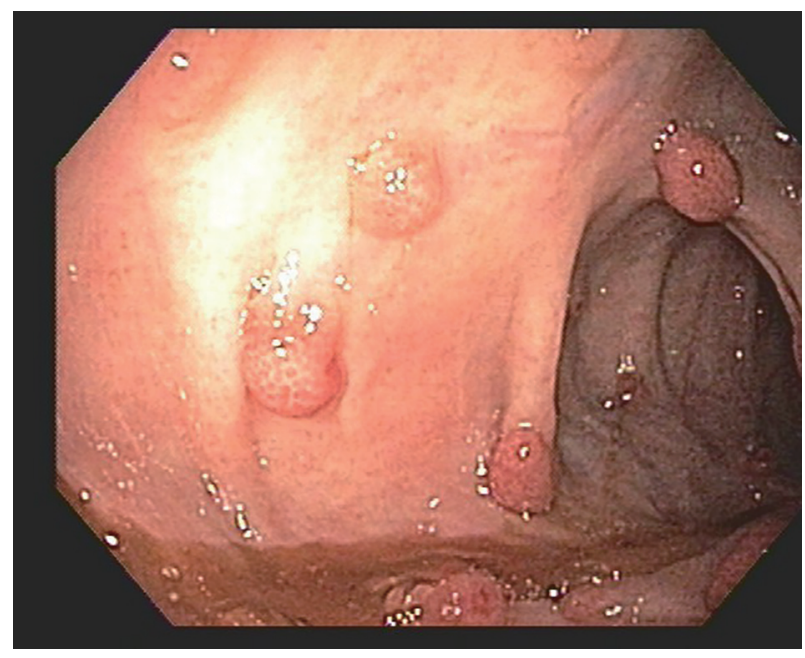

Figure 1. Hepatic flexure showing multiple inflammatory polyps. 


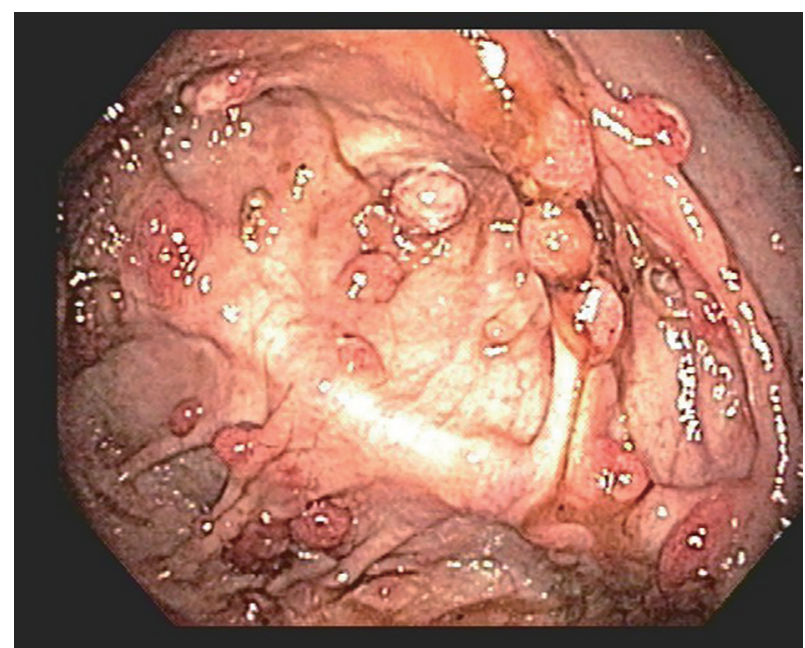

Figure 2. Cecum showing inflammatory polyps with focal adenomatous change.

and Wilma Canada in two females [4]. Since then more than 500 cases have been described in the literature of this disease [5]. Although cases have been reported worldwide, the majority are from Japan [6]. CCS is more prevalent in males than females with 3:2 ratio and commonly occurs in fifth decade of life with mean age of onset between 50 and 60 years [7]. The pathogenesis of CCS is still unclear; however, in reported cases, it can be associated with systemic lupus erythematosus, vitiligo, rheumatoid arthritis and hypothyroidism suggesting an autoimmune trigger $[1,8]$.

CCS symptoms include nausea, vomiting, diarrhea, abdominal pain, weight loss, dysgeusia or ageusia. Cutaneous abnormalities associated with CCS include alopecia, onychodystrophy/onycholysis and skin hyperpigmentation [8]. Hyperpigmentation is usually found in neck, face, palms and soles. Skin and nail changes are thought to be secondary to malabsorption and usually follow GI symptoms, although review of literature showed cases in which ectodermal abnormalities present before GI findings. CCS patients have abnormally low levels of protein, anemia and electrolyte abnormalities secondary to malnutrition and chronic diarrhea $[8,9]$. These patients can also have elevated inflammatory markers ESR and CRP.

The diagnosis of CCS is based on a combination of clinical, endoscopic and histopathological findings. Typical finding on endoscopy is diffuse GI polyposis mostly sparing the esophagus. In a case series study conducted on 14 patients at Mayo Clinic, $100 \%$ of the patients had polyps in stomach, duodenum, colon and rectum but not in the esophagus [8]. Most of the polyps are hamartomatous but inflammatory, adenomatous and hyperplastic polyps can also be present. Polyps usually show marked foveolar hyperplasia, abundant stromal edema, and mononuclear infiltrate [10]. Infiltration of IgG-4 plasma cells has also been reported in CCS polyps [8]. CCS is associated with increased incidence of GI malignancies. Both gastric and colorectal cancers have high incidence in CCS with sigmoid colon and rectum being the common sites [11]. The incidence of colorectal cancer in CCS is reported to be as high

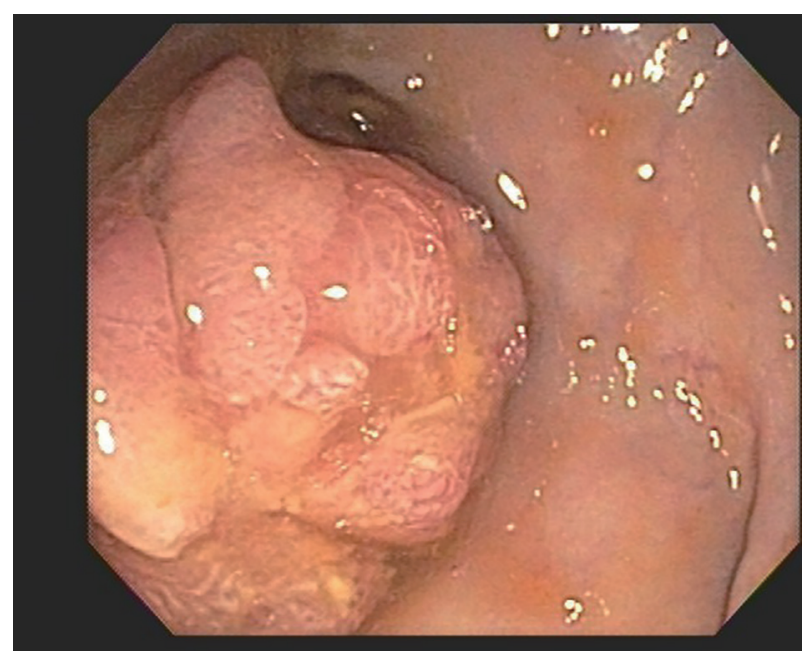

Figure 3. Sigmoid colon showing $45 \mathrm{~cm}$ polyp.

as $15 \%$ and therefore annual endoscopic screening is recommended in patients diagnosed with this disorder [12].

Management for CCS patients includes correcting electrolyte abnormalities, nutritional support and corticosteroids. Parenteral nutrition may be preferred to provide temporary bowel rest. Because of the side effects associated with the long-term use, corticosteroids are used either for achieving remission in CCS or as a bridge to introduce immunosuppressants like azathioprine [8]. Review of literature revealed cases successfully managed with anti-TNF $\alpha$ therapy like infliximab [13]. Mesalazine or 5-amino salicylic acid has also been reported to induce marked improvements [14]. Other medications used in these patients include antibiotics and acid suppressive medications. Surgical intervention is reserved for complications of CCS like bowel obstruction, prolapse and malignancy.

Untreated CCS is associated with a high mortality. Fiveyear mortality secondary to complication can be as high as $55 \%$ secondary to complications [1]. Complication of CCS includes GI bleeding, severe cachexia, congestive heart failure, intussusception, osteoporotic fractures and sepsis [9].

\section{Conclusion}

Clinicians should consider CCS in patients with unexplained diarrhea and ectodermal abnormalities especially in those of Japanese descent. Diffuse GI inflammatory polyposis sparing the esophagus on endoscopy is a hallmark of the disease. Histological examination of the biopsied polyp and intervening mucosa is helpful as well. Nutritional support and treatment with corticosteroids remain the fundamental therapy. Immunosuppresants are steroid sparing and can prevent relapse of symptoms.

\section{Consent}

Witnessed informed consent was taken from the patient to 
publish case report with images.

\section{Financial Support}

None.

\section{References}

1. Daniel ES, Ludwig SL, Lewin KJ, Ruprecht RM, Rajacich GM, Schwabe AD. The Cronkhite-Canada Syndrome. An analysis of clinical and pathologic features and therapy in 55 patients. Medicine (Baltimore). 1982;61(5):293309.

2. Katayama Y, Kimura M, Konn M. Cronkhite-Canada syndrome associated with a rectal cancer and adenomatous changes in colonic polyps. Am J Surg Pathol. 1985;9(1):65-71.

3. Goto A. Cronkhite-Canada syndrome: epidemiological study of 110 cases reported in Japan. Nihon Geka Hokan. 1995;64(1):3-14.

4. Cronkhite LW, Jr., Canada WJ. Generalized gastrointestinal polyposis; an unusual syndrome of polyposis, pigmentation, alopecia and onychotrophia. N Engl J Med. 1955;252(24):1011-1015.

5. Rubio CA, Bjork J. Cronkhite-Canada syndrome - A Case report. Anticancer Res. 2016;36(8):4215-4217.

6. Riegert-Johnson DL, Osborn N, Smyrk T, Boardman LA. Cronkhite-Canada syndrome hamartomatous polyps are infiltrated with IgG4 plasma cells. Digestion. 2007;75(23):96-97.

7. Ward EM, Wolfsen HC. Review article: the non-inherited gastrointestinal polyposis syndromes. Aliment Pharmacol Ther. 2002;16(3):333-342.

8. Sweetser S, Ahlquist DA, Osborn NK, Sanderson SO, Smyrk TC, Chari ST, Boardman LA. Clinicopathologic features and treatment outcomes in Cronkhite-Canada syndrome: support for autoimmunity. Dig Dis Sci. 2012;57(2):496-502.

9. Watanabe C, Komoto S, Tomita K, Hokari R, Tanaka M, Hirata I, Hibi T, et al. Endoscopic and clinical evaluation of treatment and prognosis of Cronkhite-Canada syndrome: a Japanese nationwide survey. J Gastroenterol. 2016;51(4):327-336.

10. Brosens LA, Wood LD, Offerhaus GJ, Arnold CA, LamHimlin D, Giardiello FM, Montgomery EA. Pathology and Genetics of Syndromic Gastric Polyps. Int J Surg Pathol. 2016;24(3):185-199.

11. Yashiro M, Kobayashi H, Kubo N, Nishiguchi Y, Wakasa K, Hirakawa K. Cronkhite-Canada syndrome containing colon cancer and serrated adenoma lesions. Digestion. 2004;69(1):57-62.

12. Nagata K, Sato Y, Endo S, Kudo SE, Kushihashi T, Umesato K. CT endoscopy for the follow-up of CronkhiteCanada syndrome. Int J Colorectal Dis. 2007;22(9):11311132.

13. Boland BS, Bagi P, Valasek MA, Chang JT, Bustamante R, Madlensky L, Sandborn WJ, et al. Cronkhite Canada Syndrome: Significant Response to Infliximab and a Possible Clue to Pathogenesis. Am J Gastroenterol. 2016;111(5):746-748.

14. Takakura M, Adachi H, Tsuchihashi N, Miyazaki E, Yoshioka Y, Yoshida K, Oryo F, Sawada T. A case of Cronkhite-Canada Syndrome markedly improved with mesalazine therapy. Digestive Endoscopy. 2004;16(1):74-78. 